\title{
Exploring Research on the Painting Formation in Higher Art Education
}

\author{
Chenfeng ZHANG \\ Shijiazhuang University, Shijiazhuang, China \\ Weina LIU \\ Shijiazhuang Information Engineering Vocational College, Shijiazhuang, China
}

ABSTRACT: Painting is an important form of visual culture, and the formation of painting is one of the fundamental factors. Considering the present situation of formal education system in teaching, the learning and research of the formation in the teaching system of contemporary painting is the key factor to build contemporary painting teaching system.

KEYWORD: Formation; Teaching

\section{GENERAL INSTRUCTIONS}

In order to know the mastery and understanding degree of the painting formation among students, 300 questionnaires were distributed to students in higher art college, then we received 300 replies. This survey covered more than ten colleges, including many majors of art education.

The results show that $97 \%$ of the students had confusion on the painting formation during artistic creation; and $90 \%$ of the students think it is necessary to start painting formation courses. This survey reveals the short of painting formation in traditional teaching and the desire for the knowledge of formation from the students.

For a long time, huge barrier had been existed between exercise and creation in art teaching, and it has important relationship with the short of formation teaching and research. Our status teaching paid great attention to the promotion of the students' ability in painting techniques and skills, the emphasis of teaching tend to master the skills ability of creat art image, there is no more system explanation teaching in the layout of pictures, just mentioned few words in shaping and color training, such as too partial, too full and so on, which makes students lack enough knowledge for the importance of its composition, controlling for the structure layout. Fuzzy art creation intention and inappropriate use of form language, all of these show the disadvantage of traditional basic training. Then, the factor of painting formation was fully exposed, and it is enough to make us reflect on the existing problems of teaching arrangement, content and way.

The famous basic teaching course in Bauhaus school provides a good example for us[1], which includes two aspects. The first is the technology, including such as sculpture, wood, metal products, pottery, stained glass, murals, woven and other studio courses. The second is the guidance for the various formation. The first kind of problems involving observation, natural research and materials analysis, and the second kind of problems including space, color, and design theories. Johannes Eaton in the memories of his teaching career wrote: "We are committed to the geometrical solution and painting formation solution with a sense of rhythm, proportion, and expression." As exploring courses for form language, the status of formation in the art and design education is obviously. However, people are generally ignored the function of formation in the pure art field[2].

As an important form factor in the artistic image performance, formation has plays an important role in the works of art creation and reflection of artistic constent, conscious learning, study and master the art form of formation, should become indispensable content in our teaching.

\section{TWO BASICAL FACTORS FOR LEARNING FORMATION}

\subsection{Basic technical elements}

\subsubsection{Points, lines and planes}

"Point" as the smallest unit of visual factors, is a very good point to study the role of visual form, and is a basic element also an important element in the plastic arts. Line is formed by the track of point, and plane is formed by collection of lines, it has different size, shape and color, is an important element to attract the visual attention. "Point moss method" in Chinese landscape paintings, and "Divisionism" of 
Europe's new impressionism are directly painting using color point, using color point collocation and parablepsia to produce the light feeling of the far of near, false or true, primary or secondary, light or heavy. Kandinsky pointed out that point is alive: "because a point itself is also a complex whole(its size and shape), it can easily imagine to be the continuation of a series of sound, that is the results of the accumulation from point into plane, even when these points are all the same." Points in the existence of the image, no matter with what kind of outer image, it is not only telling and expression of image, also play more important in formation. As Kandinsky noted the point as the meaning of the painting language, "it is essentially the most concise form", "a point make certain claims".

"Line" is the extension trajectory of "point", which is the most basic factor to clarify the visual form. Lines of simple and complex change lies in the different force value and variation of force direction, which determines the line inner voice necessarily show the tension and direction. It can produce visual contact, volume, split block, harmony, dynamics, strength and speed, can form into image independently to express the author's mood and interest. Kandinsky think different combination of lines can produce different visual effect, give person with different feelings. Staight line makes person feel hard, and curve makes person feel soft, vertical hard line makes person feel solemn and noble, horizontal line makes person feel quiet and profound, arc line makes person feel more resilient, and corrugated line make person feel like soft water and wind, etc. In some ways, "line" is the most core element in the painting style and formation. Matisse once said, "I adjust the picture variation through the density of lines."

"Plane" is more able to establish shape than "points" and "lines" in painting, it is a dense of points or lines, light and shade and colour all attach to it. The form of plane is varied, such as Picasso's "Awenon Maiden", choosing the most representative form of plane: front, back and side position, combined again and formed a new system of painting; as Chinese landscape painting said "the stone divied to three sides". Matisse in his creation of "Dance" and "Music" also said: "it seems the color and plane size has the decisive significance, because different area caused the change of their properties: free use of colour to show the amount of them determine the quality." "Plane" in different works, plays a different role, can use area, tone to adjust the stability of the painting composition.

\subsubsection{Visual field, reference system and visual illusion}

"Visual field" refers to the reflection of the outside world on the retina in specific time and place, our consciousness of outer world like far or near, big or small totally depends on visual field. Different viewpoints of distance, cause the various changes of visual features, thus make different composition of paintings. To express different purposes and feelings, many painters often choose close range of visibility to depict objects. Such as Zhongli Luo's painting "My father". Xi Guo in his book "Lin Quan Gao Zhi" also pointed out that mountain has different shape between close range and ten miles far away. Therefore, from different viewpoint and position, the object has different characteristics, thus cause the change of the formation.

"Reference system" refers to a standard or reference when make judgments of object perception features. Judgements for the different features like size, length, hardness, thickness, color, all entirely depend on the reference of each other in the images, environment plays an extremely important role, the French painter Eugene Flomontanren also has some classic arguments. As is known to all, colours will be affected by the influence of adjacent colour, a kind of color does not exist in itself, it comes from the nature of things around.

"Optical illusion" refers to an error has occurred when people perceive from the image, such as the wheel seems in reverse when the car is in high speed; the same length of line segment length caused different feeling of length caused by different direction of the arrow, etc. Due to the optical illusion has a certain influence on the painting form and picture effect, thus it should be made full use and modification in the formation, to get the picture we need.

\subsection{Visual culture experience factor}

Art is constantly developing and evolution, the tradition created by the human civilization in thousands of years is the foundation of the artist to relying on. We should study many works to accumulate visual experience.

Through the analysis of various schools of master works, the structure rules can be derived form classic works. This is also important to study the formation of painting, make the students become keen with master's works, such as order, modeling, rhythm, material and other shaping elements. The students can know the painting rules of performance art. Some painters of modern western for example Picasso etc are all start from the most ancient patterns and the original image. So some new schools of expressionism, cubism, geometric doctrine etc appear.

When the students study the ancient and modern masters works, they should apply the principle of plane composition to understand paintings, and analyze the classic works of art language and forms. And they should be good at thinking, and dissect the modeling perspective from the works, and 
understand with their own eyes. This is a rational analysis of the process, which is also a process of cultivating students' artistic accomplishment.

The modern painting art is diversified. How to choose the form of appropriate and apply in works is so fatal. The study of the formation of painting is instructive. We can get inspiration in the decomposition, combination and arrangement. And It makes the exploring the new language and creating new means is possible. This is the important point in learning the formation of painting.

\section{REFERENCES}

[1] Kandinsky. Kandinsky point line surface, Beijing, 2003.

[2] Arthur Ai Fulan. The western history of Art Education, Chengdu. 2000. 